\title{
Lifeworld conflicts and relation rebirth of couple dancing sport participants
}

\author{
Ji-Yeon Park, Yong-Jin Yoon* \\ Department of Sport \& Leisure Studies, College of Sciences in Education, Yonsei University, Seoul, Korea
}

This study aims to analyze how the conflict factors occur in lifeworld between couples are healed up through participating in the couple dancing sport, that is, how the couples are reborn to recover the relationship, and why they select the dancing sport for such an intermediate instrument. To achieve such research aims, a qualitative research has been conducted subjecting 5 couples, 10 people who both a couple is participating in the dancing sport activity. The results according to this research procedure are concluded in the following. First, the marital conflict factors occur in lifeworld include day-to-day factors, distance of conjugal relations, expression of negative emotion, etc. Second, the motives for selecting the dancing sport to resolve the marital conflict factors comprise of suggestions from surroundings, mass media, filling up the empty nest, proposals during consultation treatments, problem recognitions of conjugal relations, mutual agreement between a couple, etc. Third, the relation recovered through the couple dancing sport activity, i.e., the rebirth is deemed to be resulted from the promotion of communication opportunities through the couple dancing sport, formation of emotional communion between the couple, building new feelings between the couple, etc.

Keywords: Lifeworld conflicts, Rebirth, Couple dancing sport participants

\section{INTRODUCTION}

South Korea is recently dishonored as No. 1 in Asia and No. 3 among the OECD countries with higher divorce rate of $42.8 \%$ (The Munhwa Daily News, 2005). The increased divorce rate is resulted from the various economic factors and socio-cultural factors that change rapidly; however, many people view that the causes are basically grounded on the circumstances that reasonable solutions for the marital conflicts are yet to be found. A couple contacts each other more often than people in any other relations, experiences more in sharing closely (Fredrick and Linfeld, 1978), and encounters more frequently the conflict situations because they expose themselves to a larger extent and rely on each other (Levis and Spanier, 1991). Therefore, such marital conflicts recently become the causes that greatly threaten the stability and collapse of marriage life.

The increase of divorce rate gives rise to the collapse of family in the end and the terms referring the breakdown of a family such as runaway and erratic juvenile are raised as the core key words in social problems. Moreover, the fact that about $68 \%$ of juvenile delinquents (Ha, 2008) are from the broken home is a direct example that shows how heavily the divorce due to the marital conflicts affects the children's growth.

North America and the advanced countries in Europe where the divorce rates are high have provided aggressive supports and encouragements on the leisure or sport activities that can be enjoyable by family or couples in order to address various family or social problems caused by the increased divorce rate or marital conflicts (Andrews and Withey, 1974; Choi et al., 2006; Gordon et al., 1976; Hyun and Park, 2012; Jung and Ahn, 2012; Kang and Lee, 2008; Lee and Park, 2006; Nam and Choi, 2007; Neulinger, 1974; Park and Kim, 2013), and have settled down as the advanced countries who are leading the family leisure culture in this day. The fact that the leisure or sport activities are highly
${ }^{*}$ Corresponding author: Yong-Jin Yoon

Department of Sport \& Leisure Studies, College of Sciences in Education,

Yonsei University, 50 Yonsei-ro, Seodaemun-gu, Seoul 120-749, Korea

Tel: +82-2-2123-6196, Fax: +82-2-2123-6196, E-mail: Yoonyj@yonsei.ac.kr

Received: March 9, 2013/ Revised: March 30, 2013/ Accepted: April 11, 2013
This is an Open Access article distributed under the terms of the Creative Commons Attribution Non-Commercial License (http://creativecommons.org/licenses/by-nc/3.0/) which permits unrestricted non-commercial use, distribution, and reproduction in any medium, provided the original work is properly cited. 
valuable is proved through expanding the width of mutual understanding by pursuing the leisure activities with couple or family and cultivating the ability to effectively induce agreements on certain problems or matters of family (Ahn, 1982; Do et al., 2013; Lee, 1995; Lee and Kang, 2008; Lee and Ma, 2008; Lee and Yun, 2007; Lim, 2011; Nam, 2004 Sung, 2007; Yoon, 2008).

As appeared in the cases in the advanced countries, a logical inference can be fully established in finding the solutions to address the issues resulted from the rapid increase of divorce rate in South Korea by creating various atmospheres so that couples can participate together in leisure sport activities.

Thus, this study aims to identify the relation rebirth through clues for solving the marital conflict factors that occurs in lifeworld by participating in the couple dancing sport subjecting the participants in the couple leisure activities that are sharply increasing. This study result is considered to clarify the causes that can reduce the conflict factors between a couple; further, contribute to positive effects for reducing the divorce rate.

Therefore, this study has a different signification in promoting the leisure activities for couples and also presenting useful data for the relevant researches by identifying what are composed in the marital conflict factors that occur during their daily life and what motives are involved in selecting the dancing sport in an effort to solve such conflicts, and what rebirth factors contribute in forming new relationship of a couple through participation in the couple dancing sport. And, this study is considered to make scholarly contributions that the effects of the couple activities can be also expected in other leisure sport activities. This study identifies empirically the life world conflicts and relation rebirth of the participants who took part in the couple dancing sport. In this study, the following research questions are established to achieve this purpose. First, what constitutes the marital conflict factors that occur in lifeworld? Second, what motives involve in selecting the dancing sport to solve such conflict factors between a couple? Third, what constitutes the relation recovery i.e., the rebirth factors through the couple dancing sport activity?

\section{MATERIALS AND METHODS}

\section{Research participants}

The research participants for this study were selected as 5 couples, 10 people (men and women) who are living in $S$ city and taking part in the dancing sport activity. The researcher of this study explained the research participants the research purpose in advance, obtained prior consents from the participants about using the recorder and video camera to secure the research ethics of the qualitative research method, and conducted the study after collecting the consent forms from the research participants. Table 1 shows the general characteristics of the research participants used in this study.

\section{Data collection methods}

This study used the person-to-person, in-depth interview method in collecting data for the qualitative research method, employed the interview method by mixing the semi-structured and unstructured interviews, and constructed the question contents with 6 different question types proposed by Andrews and Withey (1974) to collect more deeply and widely the statements made by the research participants. The period to establish a rapport was given with about a month before the main interview, and the main in-

Table 1. General characteristics of research participants

\begin{tabular}{|c|c|c|c|c|c|c|c|c|}
\hline No. & $\begin{array}{c}\text { Name of } \\
\text { participant }\end{array}$ & Gender & Age & Career of dancing & Occupation & $\begin{array}{l}\text { Academic } \\
\text { background }\end{array}$ & Characteristics & $\begin{array}{l}\text { Marriage } \\
\text { duration }\end{array}$ \\
\hline 1 & Jeon YM & $\mathrm{F}$ & 43 & $3 \mathrm{yr}$ & Self-employed & University & Active and aggressive & $15 \mathrm{yr}$ \\
\hline 2 & Park DG & $\mathrm{M}$ & 46 & $3 y r$ & Public servant & University & $\begin{array}{l}\text { Very aggressive in all matters and much } \\
\text { outer-directed }\end{array}$ & \\
\hline 3 & Kim SJ & $\mathrm{F}$ & 54 & 2 yr 11 mo & Housewife & High school & Calm and introverted & $29 \mathrm{yr}$ \\
\hline 4 & Choi YM & $\mathrm{M}$ & 58 & 2 yr $11 \mathrm{mo}$ & Teacher & University & Principled and both intro-extroverted & \\
\hline 5 & Lee $\mathrm{EH}$ & $\mathrm{F}$ & 51 & $1 \mathrm{yr} 8 \mathrm{mo}$ & Housewife & University & Active and sociable & $25 \mathrm{yr}$ \\
\hline 6 & Cho GB & $\mathrm{M}$ & 52 & 1 yr 8 mo & Doctor & University & Highly motivated and introverted & \\
\hline 7 & $\mathrm{Kim} \mathrm{OH}$ & $\mathrm{F}$ & 58 & 4 yr 2 mo & Housewife & High school & Extroverted and ego centered & $35 \mathrm{yr}$ \\
\hline 8 & Choi YH & $\mathrm{M}$ & 60 & $4 \mathrm{yr} 2 \mathrm{mo}$ & Construction & University & Extroverted and sociable & \\
\hline 9 & Ahn GS & $\mathrm{F}$ & 65 & 3 yr 6 mo & Housewife & High school & Calm and both intro-extroverted & $40 \mathrm{yr}$ \\
\hline 10 & Cho JB & $\mathrm{M}$ & 68 & 3 yr 6 mo & Unemployed & High school & Extroverted and aggressive & \\
\hline
\end{tabular}

The names of research participants are presented under assumed names. 
terviews were taken from August 1 to November 30, 2012. And, each participant was interviewed 3-5 times per person, and each interview lasted for about two hours per time. The interviews were processed by each couple after the dancing sport class was finished.

\section{Data analysis method}

This study analyzed using the data processing method proposed by Guba and Lincoln (1985) on the data collected and investigated its meaning after repeating the details recorded over the interview with the participants.

\section{Research validity and reliability}

The criteria to evaluate the research may depend on how the efforts were effectively made to achieve the validity and reliability in the process of the research. In efforts to obtain the validity and reliability in this study, the triangulation of tools and analysis proposed by Denzin and Lincoln (2000) was applied to examining the authenticity and trustworthiness of the data.

\section{RESULTS}

This study adopted the interview in the participating process for its investigation to enhance the reliability of data subjecting the participants about the conflict and the recovery factors (rebirth factors) that occur in lifeworld while the couples are participating in the dancing sport together. As the result induced from the contents analysis on the data in accordance with the research procedure and the results obtained through the corresponding topic analysis, three large topics and three to five sub topics per large topic were obtained, including the marital conflicts in lifeworld.

\section{Causes of lifeworld conflicts in conjugal relations}

Various conflict factors between a couple that occur while maintaining the marriage life appeared to take place mainly in lifeworld, that is, day-to-day situations, and such conflicts were confirmed to show majorly general tendencies like different opinions in the rearing of children, household matters, housework problems, comparison of the partner with other people, evasion of responsibility each other, etc.

\section{Distant factors of conjugal relations}

The distant conjugal relations were confirmed to be gradually generated due to the lifeworld conflict factors in marriage life, and the reasons for such distant conjugal relations included the conversation severance, mutual evasion, inhibitive expression, forma- tion of distant relation, etc. Such are considered due to the efforts not to try to have opportunities to contact each other between the couple by cutting off the conversations and evading each other to avoid the conflicts and collision each other. And, it confirmed to show typical tendencies that each partner controls his/her expressions by worrying possible argument even though each has his/her own thoughts and both the couple experience the formation process toward the remote conjugal relations as the result.

\section{Expression of negative emotion}

The conjugal relations express negative emotions as being governed by the victim mentality that each partner think he/she will be ostracized and passed unnoticed as the conjugal relations become more distant. That is, the problems in expressing the positive emotions between the couple tend to be caused by the conversation severance, mutual evasion, inhibitive expression, etc that appear in the distant conjugal relations. As the result, the emotional expression such as the emotional explosion and verbal violence appear to occur in the situation when the logos cannot be controlled, and the continuous repetition of such phenomena tended to be extended toward the physical violence.

\section{Dancing sport as a clue for marital conflict solution}

The dancing sport is selected as one of options in the process of exploring leisure activities that a couple can join together in order to overcome such situations such as the lifeworld conflicts occur between the couple and increased unconcern each other. The motive contents why the dancing sport is selected as a clue to solve such marital conflicts in the selection process were identified to be due to the causes such as the suggestions from surroundings like neighbors, brothers, etc., mass media like TV programs or movies about the couple dancing sport, filling up of an empty nest, recommendations through consulting treatment, recognition on conjugal relations, and agreement between the couple, etc.

\section{Dancing sport for relation rebirth}

The main reason to start the couple dancing sport activity tends to slowly build a new conjugal relation while participating in the dancing sport activities, as an effort to solve the conjugal relation conflicts, and also, by suggestions from surroundings, mutual agreement between couples, etc. in the process of searching leisure activities that the couples can share together because of the boredom in daily life, the increased indifference between couples, etc. The sub-topics and its contents are described in the following. 


\section{Promotion of communication opportunities through the couple dancing sport}

The participation in the dancing sport showed the tendencies that the opportunities to communicate between the couple are gradually increasing during the activity situations. The subordinate factors of such tendencies appear to increase communications and necessarily promote the opportunities to reconcile while participating in the dancing sport.

\section{Formation of emotional communion between the couple}

The increase of communication opportunities through the participation in the dancing sport tended to show large contributions in forming the emotional communions between the couples that led to the increased skin ship that occurred naturally during the dancing sport activities, expanded understandings on each other, and considerations and respects on the counter part.

\section{Creation of new emotions between the couple}

The communication opportunities between the couple increase while the couple participates in the dancing sport, through which the chances are provided so that the creation of emotional communions between the couple can develop to the formation of new emotions. In such situations, the elements produced for the formation of new emotions appear to extend to the discovery of his/ her partner's attraction, increase of conjugal affections and enhancement of patience that can look after each other's wanted aspects. Many different conflict factors that occurred in lifeworld appeared to enter upon a new phase in forming conjugal relations while participating in the dancing sport.

\section{DISCUSSION}

This study aims to analyze how the conflict factors occur in lifeworld between couples can be healed up through participating in the couple dancing sport, that is, how the couples are reborn to recover the relationship, and why they select the dancing sport for such an intermediate instrument. To achieve such research aims, a qualitative research has been conducted subjecting 5 couples, 10 people who both a couple is participating in the dancing sport activity. The results obtained according to this research procedure can be concluded as follows.

First, the factors for marital conflicts occur in lifeworld include day-to-day factors, distance of conjugal relations, expression of negative emotion, etc. The daily factors of such marital conflicts can be detailized with family and children problems, evasion of responsibility, comparison with other people, etc., the factors for distant conjugal relations with lack of communication, evasion of each other, expressive suppression, and the expression of negative emotions with explosion of emotions, verbal violence, physical violence, etc.

Second, the motives to select the dancing sport for solving the marital conflict factors comprise of suggestions from surroundings, mass media, filling up the empty nests, proposals during consultation treatments, problem recognitions of conjugal relations, mutual agreements between couples, etc.

Third, the relation recovered through the couple dancing sport activity, i.e., the rebirth is deemed to be resulted by promoting communication opportunities through the couple dancing sport, forming emotional communion between couples, building new feelings between couples, etc. More in detail, the promotion of communication opportunity through the couple dancing sport brought increased communication, provision of opportunities for reconciliation, changes in life attitudes between couples, etc., and the formation of couple's emotional communion comprises increase of skin ship, extension of understandings, considerations and respects on the counterpart, etc. And, the formation of couple's new emotions contributes discovering the attractions of the counterpart, increasing the conjugal affections, enhancement of patience, etc.

\section{CONFLICT OF INTEREST}

No potential conflict of interest relevant to this article was reported.

\section{REFERENCES}

Ahn BS. A study on social meanings of the family leisure activities. Korea Sport Res 2007;18(1):3-12.

Ahn DS. A study on leisure types and marital satisfaction of house wives. Unpublished Thesis for a Master's Degree, Graduate School of Sookmyung Women's University, South Korea; 1982.

Andrews FM, Withey SB. Developing measures of perceived life quality: Results from several national surveys. Social Indicat Res 1974;1:1-26.

Choi HJ, Choi HK, Kang I. Marital conflicts according to marriage duration, difference on counter measures against conflicts, and effects on marital instability. J Korean Asso Family Relation 2006; 11(1):179-202.

Denzin NK, Lincoln YS. Handbook of Qualitative Research (2nd. ed.), Thousand Oaks, CA: Sage; 2000.

Do HS, Kim MJ, Choi MK, Kim SW. Influence on Toddlers' behavior by 
conjugal conflicts, mother's resentment and depression. J Korean Asso Child Studies 2013; 33(2):145-164.

Fredrick PL, Linfeld HM. The Process of Recreation Programming. John Wiley \& Sons; 1978.

Gordon C, Gaitz GM, Scott J. Leisure and lives: Personal expressivity accross the life span. Handbook of Aging and the Social Science (Ed.) R. H. Binstock and E. Shanas. New York, NY: D. van Nonstrand 1976;314.

Guba EA, Lincoln YS. Fourth generation evaluation. Newbury Park, CA: Sage; 1985.

Ha SH. Effects of mother's self-differentiation and marital conflicts on children's behavior. J Korean Asso Human Ecol 2008;17(4):649-660.

Hollman TB, Epperson A. Family and Leisure: A review of literature with research recommendations. J Leisure Res 1984;16:277-294.

Hyun KJ, Park SY. Economic pressure and intimacy of low income couples: an established study on diversified view of husband and wife and responding behavior against conflicts. J Korean Psychol Asso 2012;17:385-411.

Jung YJ, Ahn JS. Intermediate effects of parent-child attachment in relation to the marital intimacy of old couples and successful aging. J Korea Gerontol Soc 2012;32:185-206.

Kang EY, Lee YC. Relations between degree of participation, expression of emotions and satisfactions of participation of the couple dancing sport participants. J Korean Physic Edu Asso Girls Women 2008;22: 177-190.

Korea National Statistical Office. Statistical indicator for Korean economy. Korea National Statistical Office; 2007.

Lee JE, Yun HG. Relations between mind control, couple's communication patterns and marital satisfaction of the married women. J Korean Psychol Asso 2007;12:331-345.

Lee KY. Leisure sharing time and marital satisfaction of couples. J Korean Home Econo Asso1995;33:113-126.

Lee SM, Kang EY. Relationship between participation motives, marital in- timacy and participation satisfaction of the couple dancing sport participants. J Korean Soc Dance 2008;55:180-193.

Lee YC, Ma SR. Effects of sports for all on marital satisfaction and family health. J Korean Soc Sport Leisure Studies 2008;32:1257-1270.

Lee YS, Park KR. Influence of counter measure against marital conflict on adaptation to marriage life by house wives. J Korean Asso Human Ecol 2006;15:363-372.

Levis RA, Spanier GM. Theoizing about the quality and stability of marriage, In W. R. Burr, Hill, F. I. Nye and L. L. Reiss (Eds,) Contemporary Theories about the Familly (Vol. 2) edited by London: Free Press; 1979.

Lim BW. Analysis on attractions created in the couple skin-scuba diving activities and mechanisms of conjugal relation recovery. J Korea Exer Rehabil Asso 2011;7(1):41-55.

McIntosh PC. Sport in society. London: C.A. Watts and Co. Ltd.; 1963.

Munhwa Daily News. Sharp increase of Korea's divorce rate, dated on July 7; 2005.

$\mathrm{Nam}$ JH, Choi MR. Relation between the participation of family leisure sport activity and communications between generations and family health. Korea Sport Res 2007;18(5):3-16.

Nam MK. Effects on marital satisfaction by participation in couple dancing sport. Unpublished Thesis for a Master's Degree, School of Sport Industry, Sungkyunkwan University, South Korea; 2004.

Neulinger MH. Leisure and Recreation, New York: The Ronald Press Company; 1974.

Park TY, Kim SH. A case study for effects of therapeutic involvement to solve the marital conflicts. J Korean Family Welfare Asso 2013;17(1):3031.

Sung GS. Effects of participation in sport for all on marital satisfaction", Korea Sport Res 2007;18:687-698.

Yoon DH. A study on the balance between home-workplace and leisure activities of dual-career couple. J Korean Acad Human Resour Manage 2008;15(1):87-109. 